\title{
Antioxidants for biodiesel: additives prepared from extracted fractions of bio-oil
}

García M., Botella L., Gil-Lalaguna N.*, Arauzo J., Gonzalo A., Sánchez J.L.

Thermochemical Processes Group, Aragón Institute of Engineering Research (I3A), Universidad de Zaragoza, 50018, Zaragoza, Spain

*Corresponding author: noemigil@unizar.es

\begin{abstract}
Unlike petroleum diesel, the chemical structure of biodiesel makes it prone to oxidation during long-term storage, thus involving fuel quality deterioration. Therefore, the addition of antioxidants is usually required to meet the quality standards for biodiesel commercialization. Synthetic sterically-hindered phenols have been usually employed for this purpose as free radical scavenging antioxidants. However, naturally occurring phenolics are also available, for example, in the bio-oil produced in the pyrolysis of lignocellulosic biomass. In this work, the antioxidant potential of extracted fractions of lignocellulosic bio-oil has been evaluated. Different organic solvents were tested as extraction agents, acetate esters being the best ones for incorporating bio-oil antioxidant compounds into biodiesel. In the best case, the incorporation of a small concentration of bio-oil compounds (<4 wt. \%) led to an improvement of the biodiesel oxidation stability of $475 \%$ which, in our case, was enough to meet the European standard requirement.
\end{abstract}

Keywords: biodiesel; oxidation stability; antioxidants; lignocellulosic bio-oil; storage stability. 


\section{Introduction}

The industrial development and growth of any country is inevitably linked to fuel consumption. In this context, diesel fuels have gained an increasingly important role in the heavy transport sector. However, the rapid depletion of crude oil resources and the worldwide awareness about environmental damages have encouraged an increasing interest in alternative renewable fuels. In this context, biodiesel appears as the renewable and clean alternative to petroleum diesel to be used in conventional compression ignitions engines with little or no modification, providing less harmful emissions and enjoying the inherent advantages of being a renewable fuel [1].

Biodiesel is largely composed of a mixture of long chain fatty acid monoalkyl esters (FAME) and can be commercially produced through the transesterification reaction of natural triglycerides with a short chain alcohol. Although the technology for converting edible oils such as sunflower oil, palm oil, soybean oil, coconut oil or rapeseed oil to biodiesel has been well established [2, 3], this practice is gaining serious global concern on preserving food security of the planet. Therefore, there is a marked trend towards abolition of the use of edible oils for fuel production, encouraging the use of biofuels derived from non-edible lignocellulosic plants and wastes [4]. In this context, various non-edible crops such as jatropha, jojoba, karanja, castor and algae [57], as well as animal fats and waste cooking oils [8-10], have been successfully utilized as feedstock for biodiesel production. This wide variety of feedstock that can be used for biodiesel production leads to different properties of the final fuel, as these are heavily dependent on the parent oil composition and, more specifically, on the structure of the fatty acids chains $[1,11]$. In order to ensure the use of biodiesel in conventional diesel engines without any significant modification, the properties of both fuels have to be comparable, which is not always the case [12]. Among these, poor oxidation stability 
of biodiesel is an important drawback to be considered during extended periods of storage of this fuel [13]. The oxidation process causes changes in chemical and physical properties of biodiesel, leading to degradation of the fuel quality because of the formation of oxidation products such as aldehydes, alcohols, carboxylic acids, insoluble gums and sediments that involve fouling problems and shorten engine life [14].

The vulnerability of biodiesel to oxidation is mainly related to the presence of polyunsaturated fatty acids chains in the ester molecules, which easily react with the oxygen as soon as being exposed to air. Generally, the rate of oxidation of fatty acids alkyl esters depends on the number of double bonds and their position on the chain: the higher the number of bis-allylic methylene groups in biodiesel, the more prone is to oxidation [13-15]. Saturated compounds have good oxidation stability but, in contrast, they fail in cold temperature properties $[8,11]$.

The oxidation stability is one of the monitored parameters in the biodiesel quality standards (EN 14214 in Europe and ASTM 6751 in USA). Currently, the addition of antioxidants is usually required to fulfill the minimum threshold of oxidative stability established for biodiesel commercialization. Although oxidation cannot be entirely prevented by using antioxidants, it can be significantly retarded. Sterically hindered phenols and secondary aromatic amines are known to be free radical scavenging antioxidants that inhibit oxidation via chain termination reactions [15]. These functional groups $(\mathrm{OH}$ or $\mathrm{NH})$ contain highly labile hydrogen that can be easily abstracted by the peroxide free radical formed in the initiation and propagation steps of biodiesel oxidation, thus preventing the removal of hydrogen from a carbon of the fatty acid chain [16].

Some works have been published on the effect of the addition of natural and synthetic oxidation inhibitors on biodiesel stability. Tert-butyl hydroxyquinone 
(TBHQ), butylated hydroxytoluene (BHT), 3-tert-butyl-4-hydroxyanisole (BHA), pyrogallol (PY) and propylgallate (PG) are among the most studied synthetic antioxidants [17-20]. According to these studies, the antioxidant performance of such additives depends on factors such as the raw material used for biodiesel production or the additive concentration. In general, minimum dosages of 200-1000 ppm of these additives are required to achieve a significant improvement of the oxidation stability of biodiesel. Besides synthetic additives, naturally occurring compounds, such as tocopherols present in edible vegetable oils, have been tested as additives for biodiesel [21-24].

Natural phenolic compounds are not only found in edible oils, but can be also obtained from non-edible plants [25]. In fact, lignin, which is one of the three main building blocks of lignocellulosic biomass together with cellulose and hemicellulose, is the only renewable polyphenolic polymer, so upon thermal degradation, lignin could be a potential substitute for petroleum-based phenolics. Various thermochemical conversion technologies can be applied for fragmentation and depolymerization of lignocellulose into lower molecular weight molecules, pyrolysis being one of these [26, 27]. Bio-oil produced by the pyrolysis of lignocellulosic biomass contains over 400 different chemical compounds classified into different categories: organic acids, aldehydes, ketones, furans, sugar based components, and phenolic compounds such as phenol, dimethylphenol, guaiacol, catechol, and syringol [28]. These mono-lignols are formed from the lignin fraction and may account for $6-15 \mathrm{wt} . \%$ of the liquids derived from lignocellulosic biomass pyrolysis [29]. These valuable chemicals can be used in a wide range of applications related to the synthesis of pharmaceuticals and food additives and the production of adhesives and resins [28]. On the other hand, the known antioxidant potential of phenols is other motivation for exploring new value-added 
applications of bio-oil. Some works have been published in this field by preparing mix fuels composed of bio-oil $(10-50 \% \mathrm{w} / \mathrm{w})$ and biodiesel [30, 31]. The addition of bio-oil to biodiesel resulted in an increase of the oxidation induction temperature from 155 to $225^{\circ} \mathrm{C}$ [30], which suggests that some of bio-oil compounds act as antioxidants and protect bio-diesel from degradation. Although most of the tested properties remained within specifications, some fuel properties of the biodiesel rich phase, such as the heating value, water content, density, viscosity or carbon residue deteriorated with respect to those of neat biodiesel [31].

The potential use of bio-oil as an antioxidant for protecting biodiesel from autooxidation has been further investigated in this work. As solubility of pyrolysis oil in biodiesel is known to be relatively low [31], different organic solvents were used during the additive formulation in order to improve the extraction of phenolics from bio-oil. The antioxidant performance of the resulting additives was evaluated through their incorporation as small-dosage additives for biodiesel, and not as a mix fuel formulation.

\section{Material and methods}

\subsection{Synthesis of sunflower biodiesel}

The biodiesel employed in this study was produced from sunflower oil. Although being edible oil, sunflower oil was chosen as a model raw material for testing the antioxidant additives because of its high degree of unsaturated fatty acids [2].

Sunflower biodiesel was synthesized in our laboratory by catalytic transesterification of refined sunflower oil with methanol as aliphatic alcohol and $\mathrm{KOH}$ as alkaline catalyst (oil $/$ alcohol $=1 / 6$ molar ratio; mass of catalyst $=1 \%$ of oil mass). The mixture was heated with stirring in a batch reactor under reflux at atmospheric pressure and at a temperature of $60{ }^{\circ} \mathrm{C}$ for $3 \mathrm{~h}$. Once cooled, the liquid product was 
poured into a separation funnel and was separated into two phases: biodiesel rich phase and glycerin rich phase. Excess methanol in the biodiesel rich phase was distilled off under vacuum conditions. Then, biodiesel was washed several times with acidulated water to remove the traces of residual glycerin, unreacted catalyst and soap formed during the transesterification process. After that, biodiesel was kept under vacuum in a rotary evaporator to get rid of residual moisture and was further dried with anhydrous magnesium sulfate. Several batches of biodiesel were prepared and kept at $-18^{\circ} \mathrm{C}$.

\subsection{Preparation of the antioxidant additives and addition to biodiesel}

The bio-oil used for preparing the biodiesel antioxidant additives was kindly supplied by the Biomass Technology Group, from Enschede (The Netherlands). This bio-oil was produced during the fast pyrolysis of pinewood. The GC-MS qualitative analysis of its composition (Agilent 7890A/5975C GC-MS) showed the presence of various phenolic compounds (Table 1). Water content was determined by KF titration (Mettler Toledo V20 KF Titrator) with a result close to $33 \mathrm{wt.} \%$.

The experimental procedure for preparing the antioxidant additives from bio-oil is schematized in Figure 1. A first extraction of bio-oil compounds was carried out using an organic solvent (bio-oil / solvent mass ratio $=1 / 1 ; 25 \mathrm{~g}$ of each liquid). Ten solvents with different functional groups were tested, including esters, ketones, ethers, alcohols and aromatic hydrocarbons (Table 2). The selection of such solvents was based on different properties thereof as polarity index, water solubility and density, covering a wide range of values in order to evaluate their effect on the extraction rate of bio-oil compounds and subsequent miscibility with biodiesel. The resulting mixture was shaken and decanted in a separation funnel. Then, biodiesel was added to the separation funnel (biodiesel / bio-oil mass ratio $=1 / 1$ ) and the whole mixture was properly shaken and decanted. Two liquid phases were observed after decantation, the upper one mainly 
composed of biodiesel. This biodiesel rich phase was recovered and distillated under vacuum conditions (absolute pressure of 0.1 bar) in a rotary evaporator at $60{ }^{\circ} \mathrm{C}$ during $1 \mathrm{~h}$ in order to remove the solvent content. Then, the mixture of biodiesel and extracted bio-oil compounds was stirred and centrifuged. The insoluble fraction of bio-oil settled to the bottom of the centrifugation glass, while the homogeneous upper phase, composed of biodiesel and soluble bio-oil compounds, was carefully separated, this being the additive to be incorporated to pure biodiesel. Therefore, because of the removal of the insoluble fraction of bio-oil, the prepared additives were totally soluble in biodiesel, being composed of more than 50 wt. \% of biodiesel itself.

Eleven additives were prepared by using the ten organic solvents shown in Table 2, as well as a reference sample prepared by the direct blend of bio-oil and biodiesel with no solvent in the first extraction stage. Neat biodiesel was doped with the prepared additives at several loadings: $1,1.8,3$ and $8 \mathrm{wt}$. $\%$. The oxidation stability of these doped samples was determined just after their preparation. At the same time, the oxidative stability of the neat biodiesel used for preparing each doped sample was also analyzed in order to have a reference value for evaluating the effectiveness of the additives.

\subsection{Biodiesel characterization}

Neat and doped sunflower biodiesel were tested for some physicochemical properties. Water content in biodiesel was measured by Karl Fischer titration (Mettler Toledo V20 KF Titrator), obtaining results lower than $1000 \mathrm{ppm}$. On the other hand, viscosity and cold filter plugging point (CFPP) of some biodiesel samples were determined in strict accordance to the test methods detailed in the EN 14214 standard for these properties: EN ISO 3104 for viscosity and EN 116 for CFPP, using a FPP 5Gs Automated Cold Filter Plugging Point Analyser. Lastly, biodiesel oxidation stability 
was measured with a PetroOXY device (Petrotest Instruments GmbH \& Co. KG) according to the test method described in the standards EN 16091 y ASTM D7545. The breaking point in the PetroOXY test occurs when oxygen pressure in the hermetic measurement vessel falls $10 \%$ below the maximum pressure as a consequence of the oxygen consumption caused by biodiesel degradation. Uncertainty of these properties (oxidation stability, CFPP and viscosity) has been expressed in terms of confidence interval calculated from the standard deviation of 5 replicates of each measurement and using the critical value of the Student's t-distribution for a confidence level of $95 \%$.

The content of FAME in the neat biodiesel, as well as in one of the doped samples of biodiesel (that with the best oxidation stability result) was verified by GC-FID according to EN 14103. This method is suitable for analyzing mixtures of FAME that contain methyl esters between C6 and C24, which is the case of sunflower biodiesel. Before analyzing the biodiesel samples, a commercial solution of fatty acid methyl esters (Supelco 37 Component FAME Mix, Sigma-Aldrich) was injected and analyzed several times in order to develop a suitable analysis method for properly identifying all the peaks of FAME. Table 3 lists the most relevant parameters of the analysis method. As described in the standard EN 14103, a procedure of internal calibration was applied for FAME quantification, using methyl nonadecanoate as internal standard (SigmaAldrich analytical standard): $100 \mathrm{mg}( \pm 0.1 \mathrm{mg})$ of biodiesel were mixed with $100 \mathrm{mg}$ $( \pm 0.1 \mathrm{mg})$ of methyl nonadecanoate and both were diluted in $10 \mathrm{~mL}$ of toluene. Two aliquots of each sample were injected and analyzed by integrating the area of the identified FAME peaks. Similar methyl nonadecanoate response factors (peak area / mass) were observed in all cases: $107 \pm 7$ (mean value $\pm 95 \%$ confidence interval). For vegetable oils, EN 14103 establishes that chromatographic area percentages directly represent the mass fractions of FAME. 
Finally, the composition of some of the additives was also qualitatively analyzed by GC-MS (Agilent 7890A/5975C GC-MS) in order to identify the main phenolic compounds extracted from bio-oil and dissolved in biodiesel. The peak areas in each chromatogram were integrated and, from these data, the relative presence of phenolic compounds in each additive was estimated as the quotient between the chromatographic area corresponding to phenolics and the whole integrated area.

\subsection{Storage stability tests}

After verifying the antioxidant potential of the additives, three additional tests were conducted over time to evaluate the storage stability of both the additive itself and the doped biodiesel samples after being stored at cold temperature $\left(5-6^{\circ} \mathrm{C}\right)$ during some months. To check the storage stability of the additive, the initial antioxidant performance of the additive prepared with ethyl acetate as solvent agent was compared to the effect of its addition after five months of cold storage. In the second test, to study the storage stability of doped biodiesel, a sample of neat biodiesel was initially doped with a dosage of 3 wt. $\%$ of the ethyl acetate derived additive and, from that moment (day 0), PetroOXY time of such biodiesel sample was measured and compared up to 90 days.

Finally, the effect of the time elapsed before the incorporation of the additive was also studied. For this purpose, different samples of doped biodiesel were prepared on successive days using neat biodiesel from the same initial batch, i.e., increasingly aged, up to 90 days too. PetroOXY time of each doped sample was measured just after its preparation.

\section{Results and discussion}

\subsection{Oxidation stability of biodiesel}


Sunflower oil is mainly composed of linoleic and oleic fatty acids [2], so this oil composition will determine the composition of the biodiesel produced from it. Specifically, Table 4 summarizes the composition of the sunflower biodiesel produced in our lab, and analyzed according to EN 14103. Total content of FAME in neat biodiesel was 98.6 wt. \% and, as expected, methyl linoleate (C18:2) and methyl oleate (C18:1) were the main FAME identified, together representing more than $86 \mathrm{wt}$ \% of biodiesel. Therefore, because of the high polyunsaturated degree, poor oxidation stability is expected for this type of biodiesel.

Figure 2 shows all the results of oxidation stability (PetroOXY induction times) of neat and doped samples of biodiesel as a function of the additive dosage (1-8 wt. \%) and the type of solvent involved in the additive preparation. The results shown as $0 \%$ correspond to the PetroOxy measurements of the neat biodiesel previous to the addition of each additive. As it can be observed, there is a variation of the oxidation induction time, which ranged from 6.5 to $11.6 \mathrm{~min}$, even for samples initially from the same biodiesel. These values have been used to calculate the stability improvement for each solvent used.

As shown in Figure 2, most of the prepared additives showed a measurable positive impact on biodiesel stability, even at the lowest dosage and, as expected, the higher the dosage of additive, the better data of oxidation stability. Within the studied range of additive concentration, the evolution of PetroOXY time with additive dosage was entirely adjusted by quadratic equations, showing regression coefficients $\left(\mathrm{R}^{2}\right)$ higher than 0.999 in most cases (Table 5). According to these empirical fitting equations, the antioxidant performance of the additives prepared with both isopropyl and n-butyl acetates were the most sensitive to variations in its concentration. 
Besides the effect of the additive loading, some significant differences were clearly observed among PetroOXY times depending on the type of solvent used in the preparation of the additives. On the one hand, the use of acetone, cyclohexane, toluene and isopropanol as extraction agents during the preparation of the additives had negligible influence on the antioxidant performance if compared to the reference additive prepared by direct blending of bio-oil and biodiesel without any extraction agent. In contrast, biodiesel doped with the additives prepared through the extraction with acetate esters (methyl acetate, ethyl acetate, isopropyl acetate and n-butyl acetate) showed the best oxidation stability values for a given additive loading. In these case, the oxidation stability was noticeably increased from 11.6 min (neat biodiesel) to 33 and 36.5 min when the additives prepared with methyl acetate and ethyl acetate were added at a loading of $8 \mathrm{wt} . \%$, respectively, and from $6.5 \mathrm{~min}$ (neat biodiesel) to $37.5 \mathrm{~min}$ and 36.8 min when adding the additives prepared with isopropyl acetate and n-butyl acetate, respectively.

In order to avoid any differences arising from the dispersion in the measured oxidation stability of the neat biodiesel samples, improvement rates of PetroOXY times have been calculated with respect to the oxidation stability of each batch of neat biodiesel involved in the doping process (eq. 1). These improvement rates are shown in Figure 3.

$$
\text { OXY improvement }(\%)=\frac{\text { OXY }_{\text {doped biodiesel }}-\mathrm{OXY}_{\text {neat biodiesel }}}{\mathrm{OXY}_{\text {neat biodiesel }}} \cdot 100
$$

According to the OXY improvement rates, it can be concluded that the additives prepared through the previous extraction with n-butyl acetate and isopropyl acetate were the most effective antioxidants. The incorporation of these two additives at a dosage of 1 wt. \% led to an increase of the PetroOXY time of 125 and $150 \%$, respectively. The best results were obtained with the highest dosages of these additives ( 8 wt. \%), 
reaching improvements of the PetroOXY time up to 470 and $480 \%$, respectively. The additives prepared with diethyl ether and 2-ethyl-1-hexanol also showed high improvements of the oxidation stability, reaching increases of 380 and $350 \%$ with an additive dosage of $8 \%$, respectively. It should be emphasized again that the highest dosage of these additives did not involve an incorporation of 8 wt. \% of compounds different to methyl esters, but actually less than 4 wt. \%. In fact, GC analysis of the sample of biodiesel doped with the additive prepared with isopropyl acetate at a dosage of 8 wt. \% (best oxidation stability result) showed a total FAME content of 96.7 wt. \%, which represented a decrease of 1.7 percentage points with respect to neat biodiesel (98.6 wt. \%) because of the presence of bio-oil compounds. This FAME content meets the minimum value established in the EN 14214 standard (96.5 wt. \%), so all the other samples doped with lower concentrations of these additives will also fulfill such requirement.

When comparing our results to those shown by common synthetic antioxidants such as TBHQ (tert-butyl hydroxyquinone), BHT (butylated hydroxytoluene) or BHA (butyl hydroxy anisole), higher dosages of our bio-oil based additives are required to get similar results of OXY improvement. TBHQ appears in the literature as one of the best synthetic antioxidant additives for biodiesel showing, for example, an oxidation stability improvement of $390 \%$ at a concentration of $1000 \mathrm{ppm}$ [32]. In a previous work, Sarin et al. [24] required about $600 \mathrm{ppm}$ of both BHT and TBHQ to increase the induction period of jatropha biodiesel by $150 \%$, while we have required a dosage of 1 wt. \% (actually less than $5000 \mathrm{ppm}$ of bio-oil derived compounds) to get the same improvement rate with the additive prepared with isopropyl acetate. This fact can be explained by the dilution of phenolics into the complex matrix of bio-oil compounds. Probably not only phenols were extracted during the preparation process of the 
additives, but also other inactive compounds from an antioxidant standpoint. In other work, Rios et al. [33] observed an increase of $100 \%$ in the oxidative stability of soybean biodiesel by adding $300 \mathrm{ppm}$ of BHT. The same improvement rate has been found in our work by adding, for example, $1.8 \mathrm{wt}$. $\%$ of the additive prepared with diethyl ether or 3 wt. \% of that prepared with ethyl acetate.

In this work, the oxidation stability measurements have been conducted according to PetroOXY test, which is a rapid and increasingly extended method for this type of analyses. However, the standard procedure described in EN 14214 is not based on this method, but on the Rancimat test, which measures the conductivity of a trap solution that absorbs the volatile oxidation products. Therefore, in order to give a rough idea of how far our doped biodiesel meets the standard requirement of oxidation stability ( $8 \mathrm{~h}$ according to Rancimat test), an empirical correlation between data of both methods previously developed in our group [34] has been applied to convert the PetoOXY results to Rancimat data. These results are summarized in Table 6. As can be seen, only biodiesel doped with a dosage of 8 wt. $\%$ of the additives prepared through the extraction with acetate esters meets the minimum standard limit of $8 \mathrm{~h}$. Moreover, biodiesel samples doped with 8 wt. $\%$ of the additives prepared with both 2-ethyl-1hexanol and diethyl ether were also close to fulfilling the standard requirement.

\subsection{Analysis of other properties of biodiesel}

As expected, the GC-MS analyses of the additives demonstrated that the improvement of the biodiesel oxidation stability was related to the presence of phenolic compounds coming from the bio-oil. Guaiacol, 4-methylguaiacol, 4-ethylguaiacol, 4propylguaiacol, 5-allylguaiacol and 4-propenylguaiacol were identified in the bio-oil based additives. Among these phenolic compounds, guaiacol and 4-methylguaiacol showed the highest percentages of chromatographic area. Furthermore, a linear 
correlation between the presence of phenolic compounds in the additives (expressed as percentage of chromatographic area) and the improvement rate of the oxidation stability of biodiesel (doped at $3 \mathrm{wt}$ \%) has been found (Figure 4).

Regarding the antioxidant effect of substituted phenols, several studies have revealed that this seems to be linked with the reaction rate with the peroxyl radicals, but also with the dissociation energies of the $\mathrm{OH}$ bond. In this regard, electron donating groups substituted at ortho and para positions decrease the bond dissociation energies and increase the rate of hydrogen atom transfer to peroxyl radicals [35-37]. In our case, all the phenolic compounds identified have a methoxy substituent at ortho position, and they differ from each other in the presence of a second substituent. However, nonsignificant differences are expected in their antioxidant effect since all the second substituents are electron donating alkyl-groups at para position, except 5- allylguaiacol (meta position), so their effect on the electron density of the aromatic ring will be similar (the chain length has a minuscule effect on stability) [37]. On the other hand, an alkyl group in meta position also facilitates the abstraction of the phenolic hydrogen atom, but to a lesser extent than in the other positions. Therefore, the observed differences in the antioxidant effect of the bio-oil additives do not seem to be related to the individual effect of each phenolic compound, but to the overall extraction of phenolics.

To complete the characterization of biodiesel, Table 7 summarizes the results of viscosity and CFPP of neat sunflower biodiesel, as well as those data obtained for the biodiesel samples doped with 3 wt. \% of the additives prepared with diethyl ether, ethyl acetate and isopropyl acetate. Neither viscosity nor CFPP of biodiesel were significantly affected by the incorporation of the additives. The viscosity of biodiesel remained, in all cases, within the limits specified in the European Standard $\left(3.5-5 \mathrm{~mm}^{2} \cdot \mathrm{s}^{-1}\right)$, which is a 
good result taking into account the higher viscosity of bio-oil (about $6.6 \mathrm{~mm}^{2} \cdot \mathrm{s}^{-1}$ according to the same test method). On the other hand, cold filter plugging point of -3 ${ }^{\circ} \mathrm{C}$ or $-2{ }^{\circ} \mathrm{C}$ makes biodiesel a suitable fuel to be used in temperate climates (grades A or B according to EN 14124). However, the fact of improving biodiesel oxidation stability without damaging cold properties is also an interesting result. These properties of biodiesel depend on the type of methyl-ester constituents and they are generally opposed, i.e., a biodiesel with good oxidative stability exhibits bad cold flow properties [38].

3.3. Storage stability of biodiesel and additives

The storage stability of one of the bio-oil additives (that prepared with ethyl acetate) was evaluated by testing its antioxidant potential over time. Figure 5 shows the OXY improvement rates achieved when using several dosages of both the fresh additive (just after preparing it) and the aged additive (after five months of storage). As can be seen, the effect of the antioxidant was not deteriorated during the storage period.

Besides testing the storage stability of the additive, the storage stability of doped biodiesel was also evaluated over time. Figure 6 shows the oxidative stability profile of one sample of doped biodiesel over time. For this purpose, a sample of neat biodiesel was doped with a dosage of 3 wt. $\%$ of the ethyl acetate derived additive and, from that moment (day 0), PetroOXY time of such doped sample was measured on successive days during a period of storage of three months. Initially, the oxidative stability of biodiesel improved by almost $100 \%$ and such improvement remained virtually intact for two and a half months of biodiesel storage (Figure 6). From that moment, the oxidation stability of biodiesel started to slowly diminish. These results highlight the excellent antioxidant performance of the bio-oil derived additive over time. 
To conclude, Figure 7 shows the impact of the time elapsed before the incorporation of the additive to biodiesel. As can be seen in Figure 7, the samples of biodiesel doped within the first 20 days showed all the same PetroOXY time. From that moment, the oxidation stability of biodiesel samples doped on the following days showed a noticeable downward trend. After three months, no significant differences were found between the oxidation stability of doped biodiesel and that of the initial neat biodiesel. This fact is due only to the aging of the neat biodiesel involved in the preparation of the doped biodiesel, as the additive was proved to maintain its antioxidant potential during several months of storage (Figure 5). Therefore, the initial aging of neat biodiesel is a key factor for obtaining the expected antioxidant performance of the additive.

\section{Conclusions}

The potential use of lignocellulosic bio-oil as an antioxidant for protecting biodiesel from auto-oxidation has been investigated in this work. Different organic solvents were tested during the formulation of the additives in order to enhance both the extraction and the solution of bio-oil compounds in biodiesel. Acetate esters were found to be good solvents for this purpose. While direct blending of a small concentration of bio-oil $(<4 \%)$ and biodiesel significantly increased the biodiesel oxidation stability by $175 \%$, the previous extraction of bio-oil with isopropyl acetate or n-butyl acetate during the additive formulation led to an improvement of about $475 \%$ with the same initial dosage of bio-oil. Moreover, some storage stability tests were conducted with one of the additives, leading to the following meaningful conclusions: (i) the antioxidant potential of the additive was not deteriorated over five months of cold storage; (ii) the induction time of doped biodiesel remained virtually constant during more than two months of 
storage; (iii) the initial aging state of neat biodiesel is a key factor for obtaining the expected antioxidant performance of the additive.

\section{Acknowledgements}

The authors express their gratitude to the Spanish Ministry of Economy (Ministerio de Economía y Competitividad, MINECO) and the European Regional Development Fund for financial support (project ENE2013-41523-R), as well as to Aragón Government and European Social Fund (Thermochemical Processes Group).

\section{References}

[1] Atabani A.E., Silitonga A.S., Badruddina I.A., Mahliaa T.M.I, Masjukia H.H., Mekhilef S. A comprehensive review on biodiesel as an alternative energy resource and its characteristics. Renew Sust Energ Rev 2012; 16:2070-93.

[2] Issariyakul T., Dalai A.K. Biodiesel from vegetable oils. Renew Sust Energ Rev 2014; 31:446-71.

[3] Aransiola E.F., Ojumu T.V., Oyekola O.O., Madzimbamuto T.F., Ikhu-Omoregbe D.I.O. A review of current technology for biodiesel production: State of the art. Biomass Bioenerg 2014; 61:276-97.

[4] Directive 2009/28/EC of the European Parliament and of the Council of 23 April 2009 on the promotion of the use of energy from renewable sources and amending and subsequently repealing Directives 2001/77/EC and 2003/30/EC.

[5] Ahmed W., Nazar M.F., Ali S.D., Rana U.A., Khan S.U.D. Detailed investigation of optimized alkali catalyzed transesterification of Jatropha oil for biodiesel production. J Energy Chem 2015; 24:331-6. 
[6] Murugesan A., Umarani C., Chinnusamy T.R., Krishnan M., Subramanian R., Neduzchezhain N. Production and analysis of bio-diesel from non-edible oils - A review. Renew Sust Energ Rev 2009; 13:825-34.

[7] Ashraful A.M., Masjuki H.H., Kalam M.A., Rizwanul-Fattah I.M., Imtenan S., Shahir S.A. et al. Production and comparison of fuel properties, engine performance, and emission characteristics of biodiesel from various non-edible vegetable oils: A review. Energ Convers Manage 2014; 80:202-28.

[8] Canakci M. The potential of restaurant waste lipids as biodiesel feedstocks. Bioresource Technol 2007; 98:183-90.

[9] De Almeida V.F., García-Moreno P.J., Guadix A., Guadix E.M. Biodiesel production from mixtures of waste fish oil, palm oil and waste frying oil: Optimization of fuel properties. Fuel Process Technol 2015; 133:152-60.

[10]Ullah Z., Bustam M.A., Man Z. Biodiesel production from waste cooking oil by acidic ionic liquid as a catalyst. Renew Energ 2015; 77:521-6.

[11]Gui M.M., Lee K.T., Bhatia S. Feasibility of edible oil vs. non-edible oil vs. waste edible oil as biodiesel feedstock. Energy 2008; 33: 1646-53.

[12] Yusuf N.N.A.N., Kamarudin S.K., Yaakub Z. Overview on the current trends in biodiesel production. Energ Convers Manage 2011; 52:2741-51.

[13] Yaakob Z., Narayanan B.N., Padikkaparambil S., Unni S., Akbar M. A review on the oxidation stability of biodiesel. Renew Sust Energ Rev 2014; 35:136-53.

[14]Knothe G. Some aspects of biodiesel oxidative stability. Fuel Process Technol 2007; 88:669-77.

[15]Jain S., Sharma M.P. Stability of biodiesel and its blends: A review. Renew Sust Energ Rev 2010; 14:667-78. 
[16]Pullen J., Saeed K. An overview of biodiesel oxidation stability. Renew Sust Energ Rev 2012; 16:5924-50.

[17]Rizwanul-Fattah I.M., Masjuki H.H., Kalam M.A., Hazrat M.A., Masum B.M., Imtenan S. et al. Effect of antioxidants on oxidation stability of biodiesel derived from vegetable and animal based feedstocks. Renew Sust Energ Rev 2014; 30:35670.

[18]Dinkov R., Hristov G., Stratiev D., Boynova-Aldayri V. Effect of commercially available antioxidants over biodiesel/diesel blends stability. Fuel 2009; 88:732-7.

[19]Focke W.W., Van der Westhuizen I., Lofté-Grobler A.B., Nshoane K.T., Reddy J.K., Luyt A.S. The effect of synthetic antioxidants on the oxidative stability of biodiesel. Fuel 2012; 94:227-33.

[20] Maia E.C.R., Borsato D., Moreira I., Spacino K.R., Rodrigues P.R.P., LazarinGallina A. Study of the biodiesel B100 oxidative stability in mixture with antioxidants. Fuel Process Technol 2011; 92:1750-5.

[21]Fröhlich A., Schober S. The influence of tocopherols on the oxidation stability of methyl esters. J Amer Oil Chem Soc 2007; 84:579-85.

[22] Tang H., Wang A., Salley S.O., Simon-Ng K.Y. The effect of natural and synthetic antioxidants on the oxidative stability of biodiesel. J Amer Oil Chem Soc 2008; $85: 373-82$.

[23]Liang Y.C., May C.Y., Foon C.S., Ngan M.A., Hock C.C., Basiron Y. The effect of natural and synthetic antioxidants on the oxidative stability of palm diesel. Fuel 2006; 85:867-70.

[24] Sarin A., Singh N.P., Sarin R., Malhotra R.K. Natural and synthetic antioxidants: Influence on the oxidative stability of biodiesel synthesized from non-edible oil. Energy 2010; 35:4645-8. 
[25] Kähkönen M.P., Hopia A.I., Vuorela H.J., Rauha J.P., Pihlaja K., Kujala T.S. et al. Antioxidant activity of plant extracts containing phenolic compounds. J Agr Food Chem 1999; 47:3954-62.

[26] Yoshikawa T., Yagi T., Shinohara S., Fukunaga T., Nakasaka Y., Tago T. et al. Production of phenols from lignin via depolymerization and catalytic cracking. Fuel Process Technol 2013; 108:69-75.

[27] Amen-Chen C., Pakdel H., Roy C. Production of monomeric phenols by thermochemical conversion of biomass: a review. Bioresource Technol 2001; 79:277-99.

[28]Kim J.S. Production, separation and applications of phenolic-rich bio-oil - A review. Bioresource Technol 2015; 178:90-8.

[29] Radlein D., The production of chemicals from fast pyrolysis bio-oils. In Bridgwater A.V., Czernik S., Diebold J., editors. Fast pyrolysis of biomass: a handbook, CPL Press: Newbury, UK; 1999, p. 164-88.

[30] García-Pérez M., Adams T.T., Goodrum J.W., Das K.C., Geller D.P. DSC studies to evaluate the impact of bio-oil on cold flow properties and oxidation stability of bio-diesel. Bioresource Technol 2010; 101:6219-24.

[31] García-Pérez M., Shen J., Wang X.S., Li C.Z. Production and fuel properties of fast pyrolysis oil/bio-diesel blends. Fuel Process Technol 2010; 91:296-305.

[32] Karavalakis G., Hilari D., Givalou L., Karonis D., Stournas S. Storage stability and ageing effect of biodiesel blends treated with different antioxidants. Energy 2011; $36: 369-74$.

[33]Rios M.A.S., Santos F.F.P., Maia F.J.N., Mazzetto S.E. Evaluation of antioxidants on the thermo-oxidative stability of soybean biodiesel. J Therm Anal Calorim 2013; $112: 921-7$ 
[34] Botella L., Bimbela F., Martín L., Arauzo J., Sánchez J.L. Oxidation stability of biodiesel fuels and blends using the Rancimat and PetroOXY methods. Effect of 4allyl-2,6-dimetoxiphenol and cathecol as biodiesel additives on oxidation stability. Front Chem 2014; 2:43.

[35]Burton G.W., Doba T., Gabe E.J., Lee F.L., Prasad L. et al. Autoxidation of biological molecules. 4. Maximizing the antioxidant activity of phenols. J Am Chem Soc 1985; 107:7053

[36] Singh N., O’Malley P.J., Popelier P.L.A. Mechanistic aspects of hydrogen abstraction for phenolic antioxidants. Electronic structure and topological electron density analysis. Phys Chem Chem Phys 2005; 7:614-19

[37]Kerkering S., Koch W., Andersson J.T. Influence of phenols on the oxidation stability of home heating oils / FAME blends. Energ Fuel 2015; 29:793-9.

[38] Sharma Y.C., Singh B., Upadhyay S.N. Advancements in development and characterization of biodiesel: A review. Fuel 2008; 87:2355-73. 
Table 1. Phenolic compounds identified in the bio-oil.

\begin{tabular}{l}
\hline Phenolic compounds \\
\hline 2-methoxyphenol (guaiacol) \\
4-methylguaiacol \\
4-ethylguaiacol \\
4-vinylguaiacol \\
4-propylguaiacol \\
5-allylguaiacol \\
4-propenylguaiacol \\
vanillin \\
4-acetylguaiacol \\
levoglucosan
\end{tabular}


Table 2. Organic solvents used for bio-oil extraction.

\begin{tabular}{cc}
\hline & Organic solvent \\
\hline 1 & Acetone \\
2 & Cyclohexane \\
3 & Toluene \\
4 & Isopropanol \\
5 & 2-ethyl-1-hexanol \\
6 & Diethyl ether \\
7 & Methyl acetate \\
8 & Ethyl acetate \\
9 & Isopropyl acetate \\
10 & n-butyl acetate \\
\hline
\end{tabular}


Table 3. Method parameters for the GC analysis of biodiesel.

GC analysis of biodiesel

Instrument

Agilent 6890 GC-FID

Column

Agilent 122-2932 DB-225 MS, $30 \mathrm{~m}$ x $250 \mu \mathrm{m}$ x $0.25 \mu \mathrm{m}$

Injection volume

$1 \mu \mathrm{L}$

Injector

EPC split/splitless inlet, $260^{\circ} \mathrm{C}$, split $30 \mathrm{~mL} / \mathrm{min}$

Carrier gas

Helium, $12.5 \mathrm{psi}$

Oven program

$60{ }^{\circ} \mathrm{C}$ to $140{ }^{\circ} \mathrm{C}(5 \mathrm{~min})$ at $4{ }^{\circ} \mathrm{C} / \mathrm{min}$, then to $180{ }^{\circ} \mathrm{C}(5 \mathrm{~min})$ at $4{ }^{\circ} \mathrm{C} / \mathrm{min}$, then to $234^{\circ} \mathrm{C}(5 \mathrm{~min})$ at $1.5^{\circ} \mathrm{C} / \mathrm{min}$

Detector FID, $260^{\circ} \mathrm{C}$ 
Table 4. FAME content in neat biodiesel.

\begin{tabular}{lcc}
\hline FAME & $\begin{array}{c}\text { Retention } \\
\text { time (min) }\end{array}$ & $\begin{array}{c}\text { Mass fraction } \\
(\boldsymbol{\%})\end{array}$ \\
\hline Myristic acid methyl ester (C14:0) & 30.91 & $0.1 \pm 0.1$ \\
Palmitic acid methyl ester (C16:0) & 36.81 & $7.2 \pm 0.1$ \\
Palmitoleic acid methyl ester (C16:1) & 37.31 & $0.2 \pm 0.1$ \\
Heptadecanoic acid methyl ester (C17:0) & 40.31 & $0.1 \pm 0.1$ \\
Stearic acid methyl ester (C18:0) & 44.64 & $3.2 \pm 0.1$ \\
Oleic acid methyl ester (C18:1n9c) & 45.14 & $27.4 \pm 0.6$ \\
Linoleic acid methyl ester (C18:2n6c) & 46.67 & $59.0 \pm 0.9$ \\
Linolenic acid methyl ester (C18:3n3) & 48.32 & $0.1 \pm 0.1$ \\
Arachidic acid methyl ester (C20:0) & 53.18 & $0.3 \pm 0.1$ \\
cis-11-Eicosenoic acid methyl ester (C20:1) & 53.72 & $0.1 \pm 0.1$ \\
Arachidonic acid methyl ester (C20:4n6) & 57.59 & $0.2 \pm 0.1$ \\
Behenic acid methyl ester (C22:0) & 61.98 & $0.6 \pm 0.1$ \\
Lignoceric acid methyl ester (C24:0) & 70.48 & $0.2 \pm 0.1$ \\
\hline Total FAME (\%) & & $98.6 \pm 2.6$ \\
\hline
\end{tabular}


Table 5. Empirical fitting equations for the evolution of PetroOXY time of biodiesel (y) with the additive dosage $(\mathrm{x})$.

\begin{tabular}{lcc}
\hline Organic solvent & \multicolumn{1}{c}{ Fitting equation } & $\mathbf{R}^{2}$ \\
\hline No organic solvent & $\mathrm{y}=-0.074 \cdot \mathrm{x}^{2}+2.69 \cdot \mathrm{x}+9.61$ & 1.0000 \\
Acetone & $\mathrm{y}=-0.030 \cdot \mathrm{x}^{2}+2.06 \cdot \mathrm{x}+10.43$ & 0.9989 \\
Cyclohexane & $\mathrm{y}=-0.015 \cdot \mathrm{x}^{2}+1.77 \cdot \mathrm{x}+10.47$ & 0.9993 \\
Toluene & $\mathrm{y}=-0.070 \cdot \mathrm{x}^{2}+2.88 \cdot \mathrm{x}+9.69$ & 0.9994 \\
Isopropanol & $\mathrm{y}=-0.061 \cdot \mathrm{x}^{2}+2.50 \cdot \mathrm{x}+9.79$ & 0.9988 \\
2-ethyl-1-hexanol & $\mathrm{y}=-0.251 \cdot \mathrm{x}^{2}+5.05 \cdot \mathrm{x}+6.73$ & 0.9993 \\
Diethyl ether & $\mathrm{y}=-0.141 \cdot \mathrm{x}^{2}+4.19 \cdot \mathrm{x}+6.88$ & 0.9993 \\
Methyl acetate & $\mathrm{y}=-0.164 \cdot \mathrm{x}^{2}+3.99 \cdot \mathrm{x}+11.48$ & 0.9996 \\
Ethyl acetate & $\mathrm{y}=-0.196 \cdot \mathrm{x}^{2}+4.67 \cdot \mathrm{x}+11.44$ & 0.9995 \\
Isopropyl acetate & $\mathrm{y}=-0.406 \cdot \mathrm{x}^{2}+7.02 \cdot \mathrm{x}+7.18$ & 0.9916 \\
$\mathrm{n}$-butyl acetate & $\mathrm{y}=-0.456 \cdot \mathrm{x}^{2}+7.41 \cdot \mathrm{x}+6.70$ & 0.9994 \\
\hline
\end{tabular}


Table 6. Rancimat induction times of doped biodiesel samples, calculated according to an empirical correlation [34].

\begin{tabular}{lcccc}
\hline $\begin{array}{l}\text { Organic solvent used for } \\
\text { preparing the additive }\end{array}$ & $\mathbf{1} \%$ & $\mathbf{1 . 8}$ \% & $\mathbf{3} \%$ & $\mathbf{8} \%$ \\
\hline No organic solvent & 4.1 & 4.4 & 5.0 & 6.8 \\
Acetone & 4.0 & 4.3 & 4.8 & 6.5 \\
Cyclohexane & 4.0 & 4.3 & 4.6 & 6.3 \\
Toluene & 3.9 & 4.4 & 5.0 & 7.2 \\
Isopropanol & 3.9 & 4.3 & 4.9 & 6.6 \\
2-ethyl-1-hexanol & 4.0 & 4.6 & 5.1 & 7.6 \\
Diethyl ether & 3.8 & 4.4 & 5.4 & 7.8 \\
Methyl acetate & 4.6 & 5.1 & 5.8 & 8.0 \\
Ethyl acetate & 4.7 & 5.4 & 6.2 & 8.6 \\
Isopropyl acetate & 4.7 & 5.5 & 6.1 & 8.8 \\
n-butyl acetate & 4.5 & 5.3 & 6.4 & 8.7 \\
\hline
\end{tabular}

The $95 \%$ confidence interval for all data in the table is $0.1 \mathrm{~h}$. 
Table 7. Viscosity and cold filter plugging point of biodiesel samples (3 wt. \% of additive in the doped samples).

\begin{tabular}{lcc}
\hline Biodiesel sample & $\begin{array}{c}\text { Viscosity at } \\
\mathbf{4 0}^{\mathbf{}} \mathbf{C}\left(\mathbf{m m}^{\mathbf{2}} \cdot \mathbf{s}^{-\mathbf{1}}\right)\end{array}$ & $\begin{array}{c}\text { CFPP } \\
\left({ }^{\mathbf{0}} \mathbf{C}\right)\end{array}$ \\
\hline Neat biodiesel & $4.18 \pm 0.01$ & $-3 \pm 1$ \\
Biodiesel doped with the diethyl ether additive & $4.29 \pm 0.01$ & $-3 \pm 1$ \\
Biodiesel doped with the ethyl acetate additive & $4.36 \pm 0.01$ & $-3 \pm 1$ \\
Biodiesel doped with the isopropyl acetate additive & $4.43 \pm 0.01$ & $-2 \pm 1$ \\
\hline
\end{tabular}




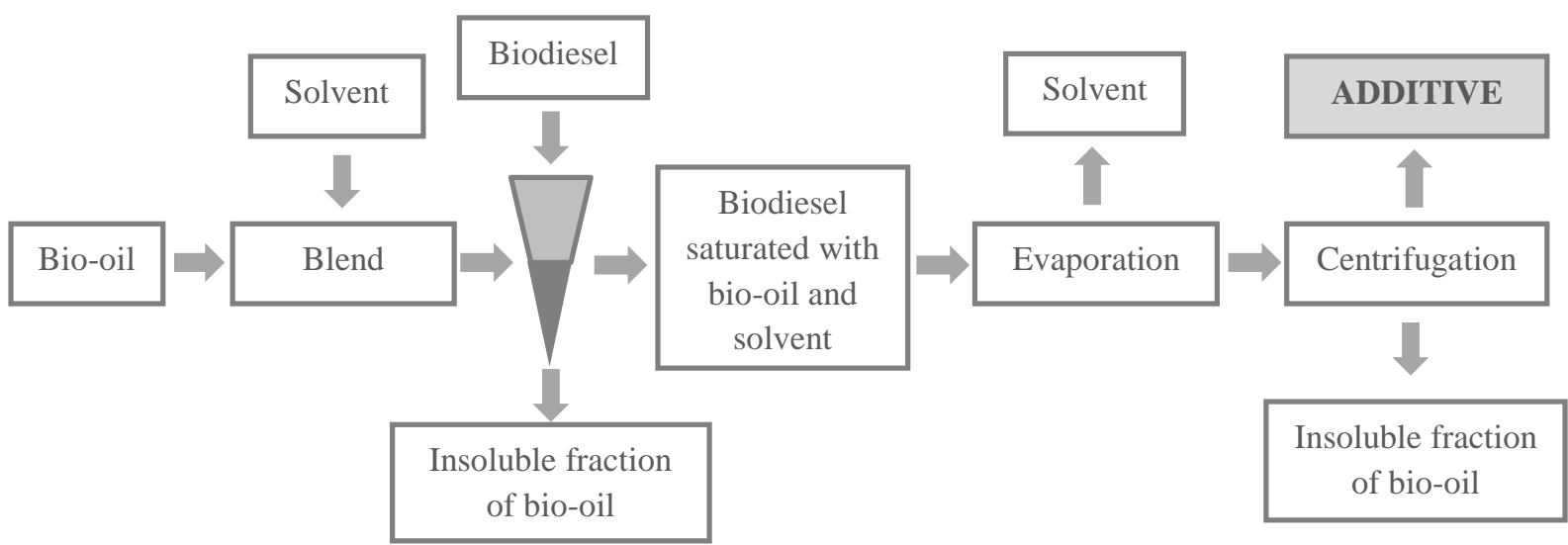

Figure 1. Process for obtaining the bio-oil based additives. 

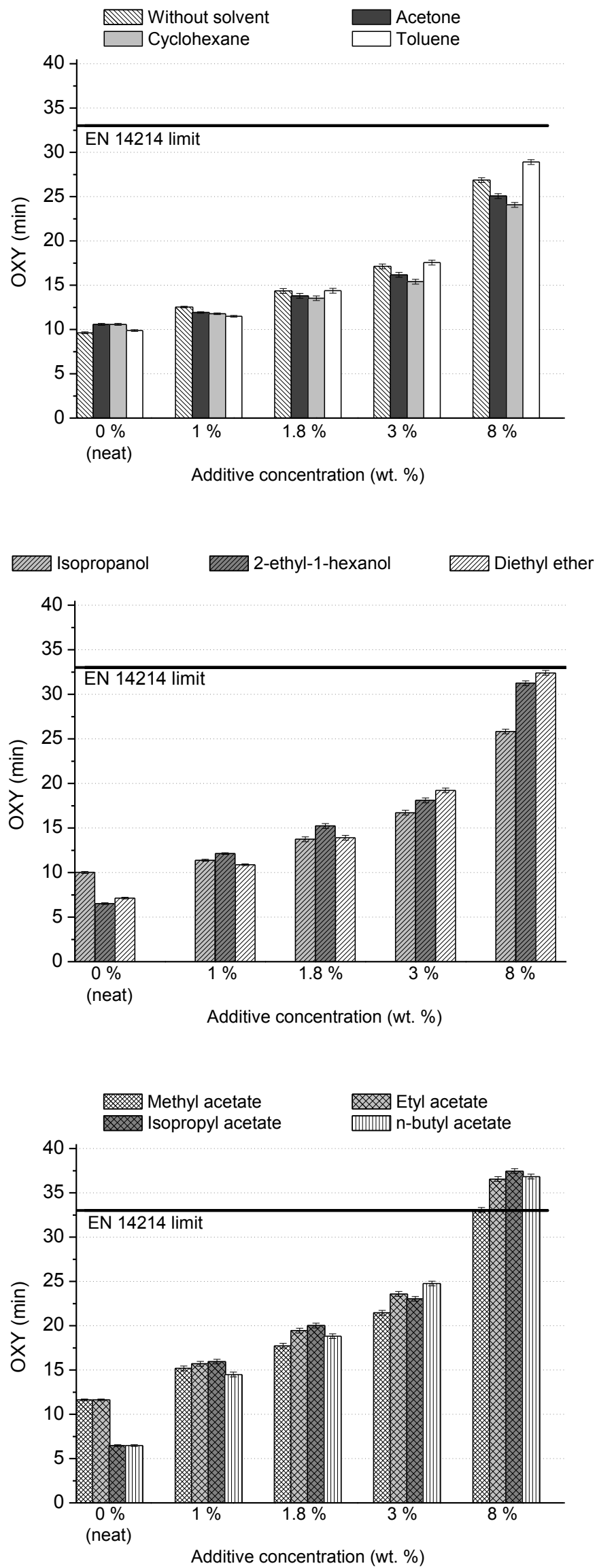

Figure 2. PetroOXY stability of biodiesel doped with the bio-oil based additives. 

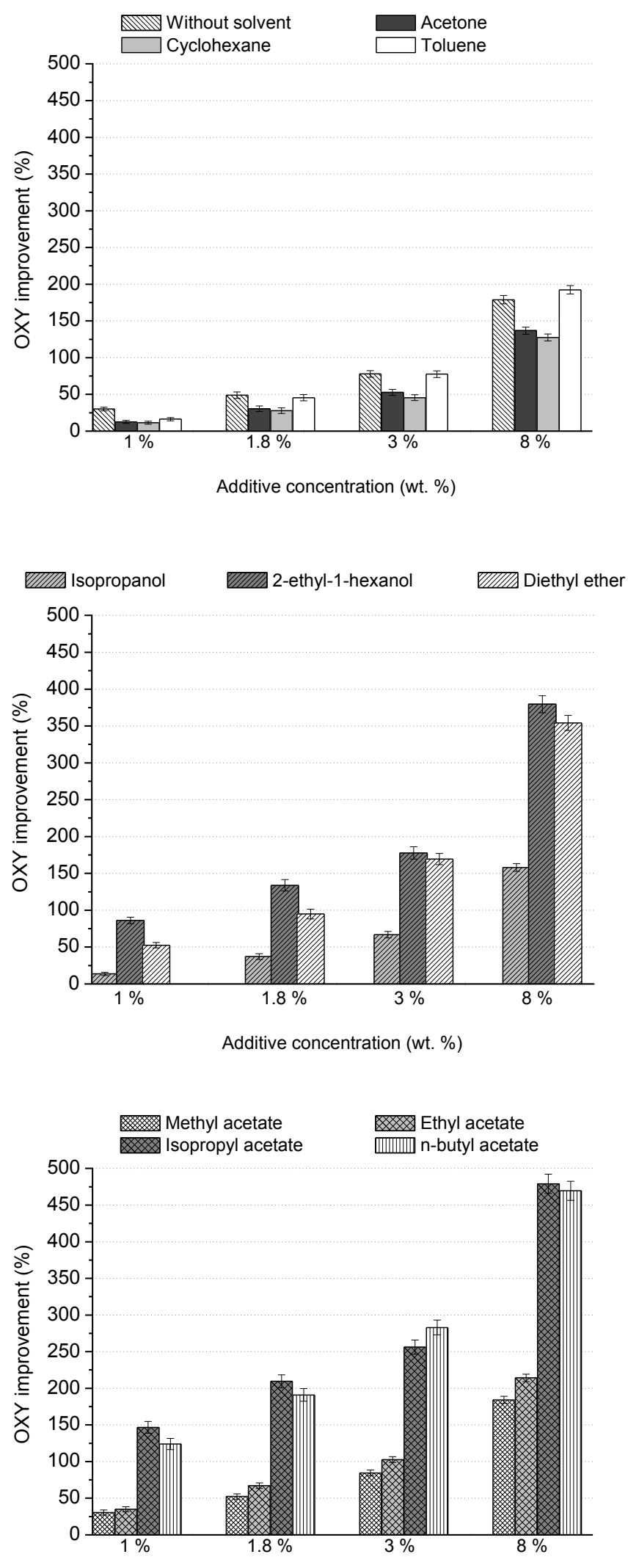

Additive concentration (wt. \%)

Figure 3. Improvement rate of the oxidation stability of sunflower biodiesel after adding the bio-oil based additives at different loadings. 


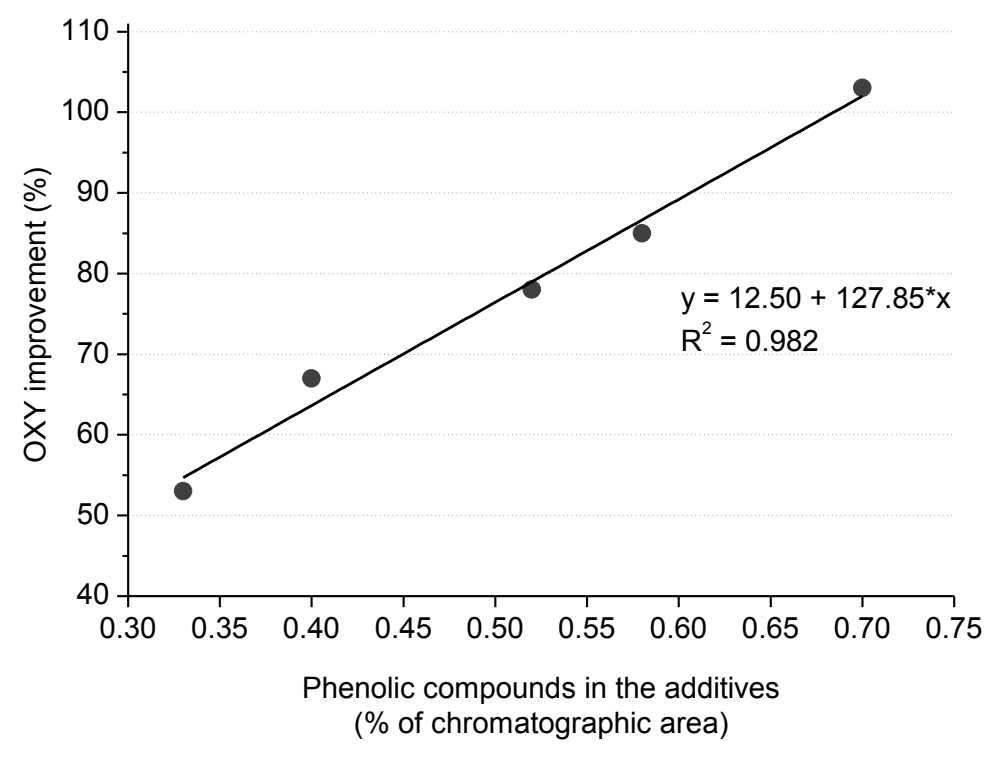

Figure 4. Improvement rate of the oxidation stability of biodiesel (doped with 3 wt. \% of additive) as a function of the presence of phenolic compounds in the additives. 


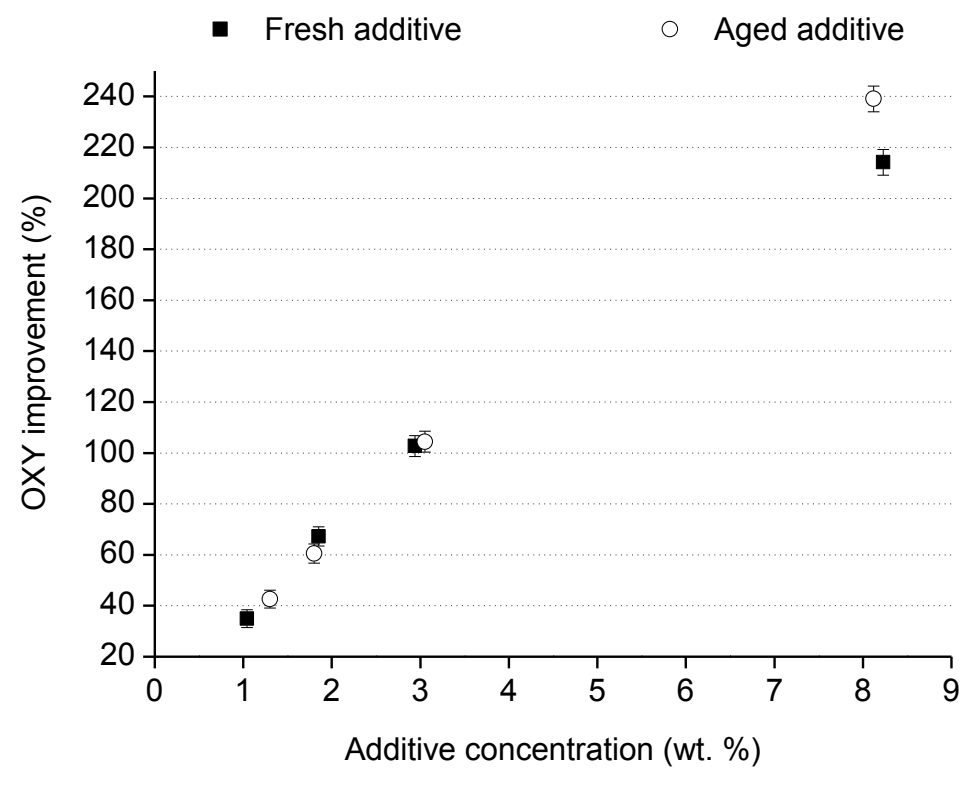

Figure 5. Comparison of the antioxidant performance of the additive prepared with ethyl acetate just after its preparation (fresh additive) and after storage (aged additive). 
* Doped biodiesel (ethyl acetate as solvent)

- Neat biodiesel

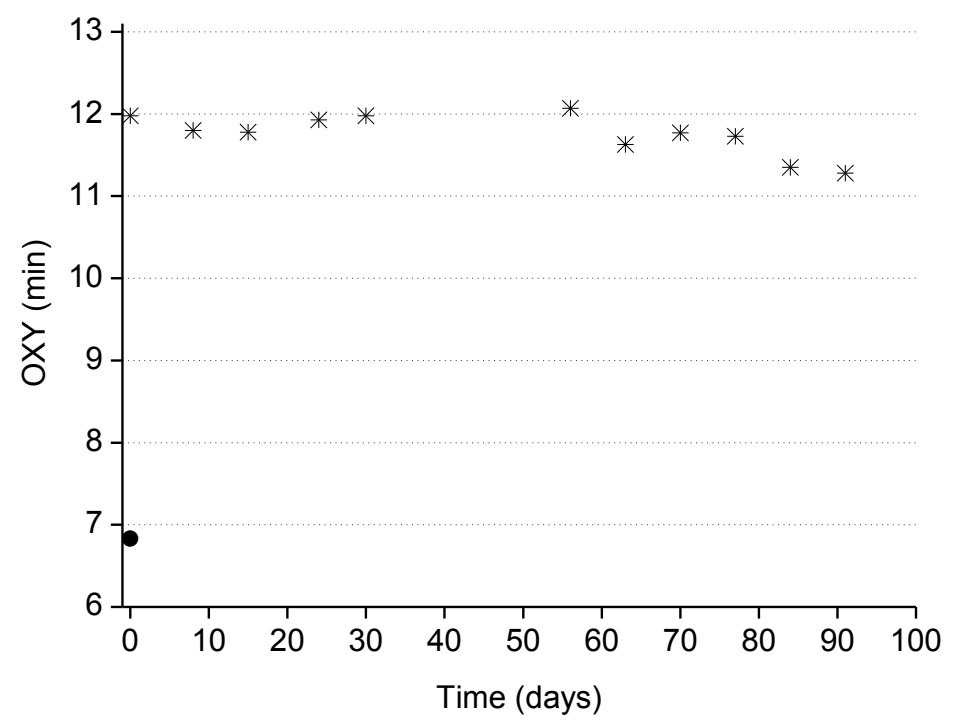

Figure 6. Oxidation stability of doped biodiesel over time. 


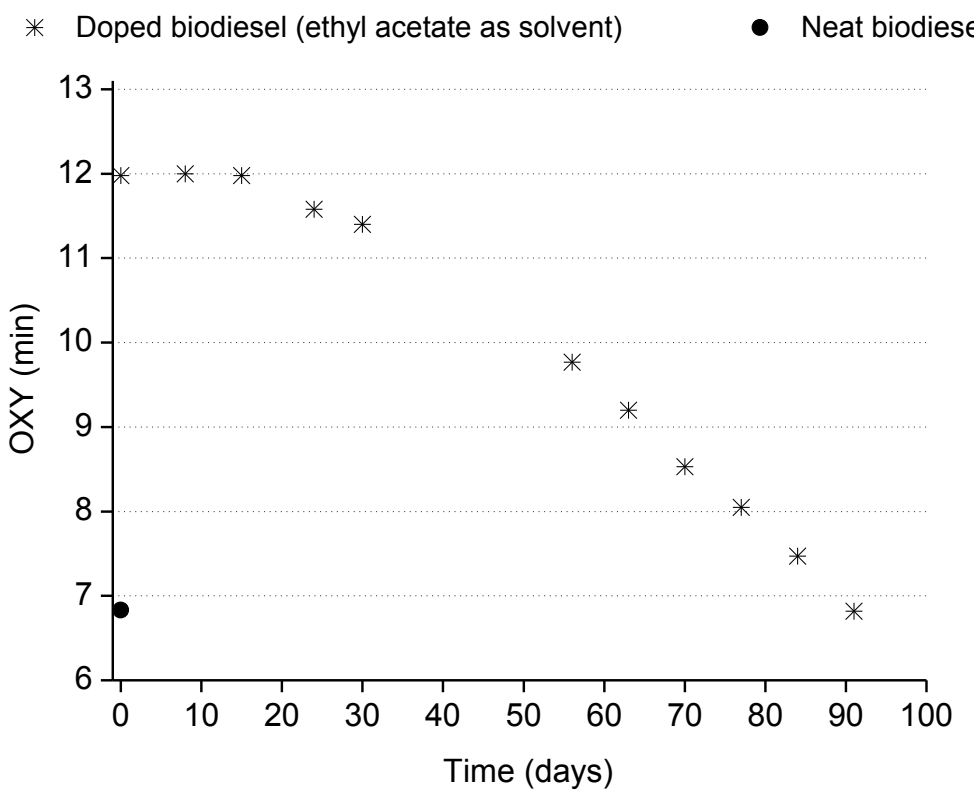

Figure 7. Effect of time elapsed up to additive incorporation on biodiesel oxidation stability. 